\title{
Ethical Issues in The Treatment of Transsexual Patients
}

\author{
Pragya Lodha ${ }^{1}$, Avinash De Sousa ${ }^{2}$ \\ ${ }^{1}$ Research Assistant and Clinical Psychologist, Desousa Foundation, Mumbai. \\ ${ }^{2}$ Research Associate, Department of Psychiatry, Lokmanya Tilak Municipal Medical College, Mumbai.
}

Corresponding Author: Avinash De Sousa

E-mail: avinashdes888@gmail.com

\begin{abstract}
The trans community, under the spectrum LGBTQ is one of the minorities that faces challenges on various psycho-social, economic and political fronts. One of the greatest challenges that these people face is not only being discriminated socially but also receiving discriminated treatments. One of the bigger challenges in the health domain is that of mental health. There is a lack of sensitivity, appropriate understanding and sufficient treatment modalities for treatment of trans community of patients. The present paper provides an overview of the various ethical issues encountered when treating transsexual patients in clinical practice.
\end{abstract}

Key words: transsexuals, treatment, mental health, ethics.

Transgender, transsexual, and gender non-conforming individuals are a part of cultures around the world. 'Trans' is an umbrella term used for persons whose gender identity does not conform to their biological sex [1-2]. A person's gender identity is their own sense of whether they are male or female, or neither. Some transgender people identify themselves with their changed gender: from male to female or female to male. However, others see themselves as members of a third sex. Officially now, the transgender is the third gender, in recognition and identity. Though difficult to quote an exact census number, globally, the population estimates to around 25 million and India has one of the largest population of trans people in the world, with an estimated population of 5 lakhs (Indian Census 2011) [3]. More than half of all the trans individuals suffer from a mental illness. The fear of 'coming out' and being subjected to discrimination for sexual orientation and gender identities, can lead to depression, posttraumatic stress disorder, thoughts of suicide and substance abuse- which is three-fold greater than that among heterosexual adults [4]. There is a dearth of sensitized treatment, specialised approaches to therapy and recognition of mental health issues in the transsexuals.

Replacing the term transvestite, 'transgender' was coined in 1980s [5]. For a clearer understanding, Eyler and Wright (1997) gave a nine-point gender continuum. Their continuum depicts a range of possible gender identities, from "female-based" identities to "male-based" identities, with "bigendered" identities [6]. The terms Transgender / transsexual / trans are used interchangeably in this article for addressing various aspects of the issues.

As a community, transgender is a part of the LGBTQ (Lesbian, Gay, Bisexual, Transgender, Queer) community. They fall under a minority and are subject to various psycho-social discriminations and societal prejudices. The stigma and discrimination against them leaves them subjected to multiple issues with their well-being: rejection at home, struggle for societal identity 
and acceptance, access to health care and well-being and to ingress fundamental human rights [7]. However, the awareness and advocacy for LGBTQ rights with an increased sensitivity towards the community, has grown with time.

Despite the Indian government's recognition of the transgender as the 'third gender' (NALSA judgement, April 2014) [8], the trans community continues to face discrimination and is denied their fundamental rights (in many instances). With the disparity of health care services available to the trans community, this review is a focus on the ethical issues involved in the psychiatric treatment of transsexual community.

There are some cardinal ethical considerations assigned to the treatment of trans community and include the following [9]:

a) Autonomy - Transgender patients have the right to have their self-identification respected by staff, and their preferred name and gender identity should be recorded as they wish it to be. Transgender patients have the right to make healthcare decisions collaboratively with their providers under the principle of informed consent.

b) Nonmaleficence - Healthcare providers may need to reflect on their approach to gender identity and patient experience and should critically assess gaps in their knowledge and acceptance of gender nonconforming patients

c) Justice - The principle of justice affirms that transgender patients are equally entitled to a fair distribution of healthcare resources; however, transgender patients are less likely to have health insurance and access to mental health services.

d) Beneficence - Mental health providers with expertise in trans-affirmative mental health care that is respectful, aware, and supportive of the life experiences of transgender people are scarce. Transgender patients may view mental health assessments as an important gateway to accessing surgeons, endocrinologists, and legal changes. This perception could create a vulnerable power differential, making patients incredibly cautious during initial appointments.

The emergent transgender consciousness and political activism have had important implications for the field of mental health. It has persuaded the clinicians to rethink their assumptions about gender, sexuality, and sexual orientation. A "trans-positive" or "trans-affirmative" disposition to counselling is the need of the hour [5] that affirms transgendered persons; advocates for their political, social, and economic rights; and educates others about such issues. This approach is similar to the practice of "sex-positive" therapy $[5,10]$.

Transgender people may seek mental health care for a number reasons; in addition to mental health issues relating to or resulting from one's gender identity. Research studies have also examined the wider views and needs of transgender people in relation to psychotherapy. It has been observed that therapy is also sought for relationship satisfaction, emotional health concerns and affirmative therapy among the trans community [11]. Vulnerability in relation to health issues has been identified with respect to various factors including: a lack of safe environments, poor access to health services, challenges to the continuity of care-giving by their family and friends, and poor mental health resources. Some people also report concerns around harassment, discrimination, physical violence and sexual abuse. Engaging in avoidant behaviours that compound their feelings of marginalization and exclusion, entering prostitution in the absence of financial support and illicit drug use are other noted problems among the community. Feelings of shame and unworthiness have been found to be common and some people articulate thoughts of self-harm and suicide. Homelessness, social ostracization and transphobic reactions and stigma related issues are other problems that the people of this community face that affects their emotional and mental health [12]. While some may be seeking specific assistance for gender-related themes, others are seeking assistance with depression, anxiety, or other clinical concerns unrelated to their gender identity [13]. It is commonly observed that mood spectrum disorders and psychotic disorder are seen to occur in the trans community as well. 
Transgender and gender nonconforming people, in general, have three types of need for mental health [14].

i. Exploration of gender identity: This includes determining exactly what one's gender identity is, coming to terms with this gender identity, self-acceptance and individuation, and exploring individual-level ways to actualize this identity in the world. This may also include preparation and assessment for various gender affirming treatments and procedures.

ii. Coming out and social transition: This includes coming out to family, friends, and coworkers, dating and relationships, and developing tools to cope with being transgender in a sometimes, transphobic world.

iii. General mental health issues, unrelated to gender identity: The variety of mental health concerns experienced by transgender people include mood disorders, generalized anxiety, substance abuse, and post-traumatic stress disorder (PTSD).

Health care providers in the mental health as well as medical set up, are often unaware of the specific public health concerns of the trans community who fall under the minority group consumers [15] which adds to the psycho-social construct experience of marginalization [16]. This additionally entails ethical concerns that pertain to the health and treatment of the transgender community [12].

There are several challenges specific to the mental health of the trans persons that the community faces, especially so in the Indian scenario:

1. In the past, mental health issues for transgender people were narrowly viewed through a diagnostic lens of the gender identity disorder. This led to pathologizing of the person's unique psychosocial experiences, therefore, limiting therapeutic responses and treatment options [12]. The diagnosis of "trans-sexualism" first appeared in the International Statistical Classification of Diseases and Related Health Problems 9 in 1975 and, in 1980, in the Diagnostic and Statistical Manual of Mental Disorders III. However, recent research advancements (beginning since 2013) have confirmed that being transgender is not a mental illness. But in India, little medical research has been conducted on the issues of trans persons and the notion that being transgender is a mental illness continues to pervade.

2. Health and social care needs along with experiences, vary across the lifespan. Identities for the young people often take shape by findings ways to integrate their identity into their cultural background, personal characteristics and family circumstances. Corliss and others [17] show through their research that the experiences of young transgender people; therefore, young people continue to remain invisible and their concerns often neglected [12].

3. There is no expert clinical consensus nor clinical guidelines regarding the treatment of prepubescent children who meet the diagnostic criteria for gender dysphoria [18]. It is believed that gender dysphoria usually translates from adolescence to adulthood, however, the World Professional Association for Transgender Health (WPATH) has discussed that such is not the case. In their latest Standards of Care, merely 6 to 23 percent of boys and 12 to 27 percent of girls treated in gender clinics have shown persistence of their gender dysphoria into adulthood [19].

4. Sex change therapies are a practice till date despite the known fact that it is incorrect and impossible to medicate someone in order to make them conform to their biological sex. This raises a humongous ethical dilemma in the practice of those professionals who promise to change the 'preference of sexuality' as a consequence of the sex change surgery. There are several instances when children, adolescents and young adults have been taken to psychotherapists or counsellors by their parents with the notion that counselling can transform rather 'correct' their sexuality. However, these are myths and anybody who conforms to these practices in affirmation would be suspected on ethical (health care) practices. As opposed to this view, sex reassignment therapies are meant for those who wish to get themselves biologically corrected in order to conform to their psychological sex or the gender they wish to conform to (which is usually biologically the opposite). 
5. The assessment before the sex reassignment surgeries and accessing hormone treatment remain at the merciful approval of the practitioners, some of them who continue to give a diagnosis of Gender Identity Disorder (the revision of Gender Identity Disorder in DSM IV TR has evolved to that of Gender Dysphoria in DSM 5 which implies the treatment of distress, depression or anxiety due to the non-conformity to the gender and does not involve any techniques or therapies to dissuade the personal choice / preference of an individual to identifying with a gender). The process of pre-counselling before the sex reassignment surgery may miss the underlying emotional factors and many a times, involves dissuasion rom the sex reassignment surgery in order to conform to the biological sex of the individual. Ethically, before the surgery, the individual is made to undergo various social norms and make lifestyle choices so as to prepare them for the post-surgery life.

6. Post-surgery and post hormone treatment care and counselling is missing, which is a crucial aspect in order to build and settle the transformations in the patient.

7. Unrequired ECT (electroconvulsive therapy), tying the patients to beds and institutionalisation are resorted to for convincing patients about the 'consequences of sex change' and instead stand the chance of an ethical dilemma. Unfortunately, several practitioners resort to giving ECT in order to prevent the sex reassignment surgery for the individual thinking it is part of the treatment, however, one must be aware that this means is hoax.

8. As a result of the apparent stressors, an increasing number of transgender people are seeking therapy. However, therapists often lack the skills to work effectively with transgender clients and are often insensitive, ignorant and unaware regarding the several transgender issues [20]. Many mental health professionals and medical practitioners lack an understanding of the LGBTQ spectrum health issues. Thus, an expertise to treat their concerns with an understanding of the ethical standpoints is missing.

9. The distinct needs of families with a transgender family member have often been neglected [21] and children are increasingly in need of support. It has been clearly identified that access to family and couples therapy remains limited if it exists in the first place [22]. It transpires that most professionals in mental health services have received no training on transgender issues and there are visible shortcomings in terms of mental health education and curriculum developments [23-24]. This denies the trans community the treatment they deserve. However, in the present times, the training for the same has taken a start but is a long way to go.

10. It has been noticed that practitioners harbour personal biases and prejudices in taking up trans patients for therapy or treatment. Psychiatrists and psychotherapists have a biased choice for taking up patients for treatment and thus may invariable deny the required and optimal mental health services needed by the trans individuals.

11. Counselling and psychotherapies also need a branch of specialisation in order to understand and appropriately address the concerns and mental health issues of trans communities that are amplified due to multiple concerns. After having recognised the 'third' gender, the education and training centres fail to be inclusive in terms of providing the care for trans community.

12. Schools and colleges lack a curriculum to understand the sensitivity of the health problems and other concerns of the trans community thus the inclusivity of trans members is a continued struggle in the educational and socio-political sphere. This further leads to the lack of awareness and understanding required to incorporate the needs and concerns of their community.

13. Gender dysphoria clinics are a far-fetched dream in India and other places. It is the need of the hour to incorporate and make available the deserving treatment to the trans individuals. 
There are various suggestions that can be kept in mind in order to tackle the ethical dilemmas with regard to the treatment of the third genders in our country:

1. Primary care settings must offer a safer environment for transgender people to bring up mental health concerns and may be easier to access than mental health services.

2. Every intake for care should include a mental health history and an assessment for active mental health concerns.

3. Screening should include primary mental health problems, environmental and social stressors, and gender-related needs. Screening also requires provision of appropriate referrals to transgender-affirming mental health services when needs are identified.

4. When there is a trans patient that a mental health professional is unable to handle, one must choose to refer them to mental health professionals who specialise in the field of LGBT mental health and thus will be more equipped to treat them.

5. Gender Identity Disorder should be a discarded phenomenon. Gender dysphoria must be understood in the rightful definition of the underlying depression or distress due to gender confusion or social ostracization and not a pathological identity / personality.

\section{CONCLUSIONS}

The trans community, under the spectrum LGBTQ is one of the minorities that faces challenges on various psycho-social, economic and political fronts. One of the greatest challenges that these people face is not only being discriminated socially but also receiving discriminated treatments. One of the bigger challenges in the health domain is that of mental health. There is a dearth of sensitized treatment, specialized approaches to therapy and recognition of mental health issues in the transsexuals. However, there is scope for improvement. Mental health professionals dealing with these population must have a thorough awareness of the various ethical dilemmas involved when treating such special groups.

\section{REFERENCES}

1. Balakrishnan VS. Growing recognition of transgender health: stigma, discrimination and lack of legal recognition remain major barriers for transgender people to access the health services they need. Bull WHO 2016;94(11):790-2.

2. Deutsch $\mathrm{MB}$, editor. Guidelines for the primary and gender-affirming care of transgender and gender nonbinary people. University of California, San Francisco; 2016.

3. Nagarajan R. First count of third gender in census: 4.9 lakh. The times of India.2015 May 30. News India, [Newspaper on the Internet]

4. National Alliance on Mental Illness. LGBTQ. [Internet]. 2017. Available from http://www.citethisforme.com/guides/vancouver/how-to-cite-a-website

5. Carroll L, Gilroy PJ, Ryan J. Counseling transgendered, transsexual, and gender- variant clients. J Couns Dev 2002;80(2):131-9.

6. Lodha P. Better Mental Health Services for Trans-Persons in India-There is a Need for Understanding, Training and Infrastructure. [Internet]. January 21,2017. Available from http://newsnviews.online/news-n-views/better-mental-health-services-for-trans-persons-in-indiathe-need-for-understanding-training-and-infrastructure/

7. Ramya Jawahar Kudekallu. [Internet]. Why Transgender Community is struggling inspite of the NALSA judgment. March 3, 2017. Available from http://www.dailyo.in/politics/transgendernalsa-judgment-aadhar-card-gender-rights-self-identification/story/1/15462.html.

8. American Association for Marriage and Family Therapy, California Division. LGBT affirmative therapy: Tips for creating a more lesbian, gay, bisexual, transgender, and gender inclusive practice from the AAMFT Queer Affirmative Caucus.

9. Hann M, Ivester R, Denton GD. Bioethics in Practice: Ethical Issues in the Care of Transgender Patients. The Ochsner Journal 2017;17(2):144-5.

10. Benson KE. Seeking support: Transgender client experiences with mental health services. J Feminist Fam Ther 2013;25(1):17-40.

11. Keogh B, Daly L, Sharek D, De Vries J, McCann E, Higgins A. Sexual health promotion programme: Participants' perspectives on capacity building. Health Educ J 2016;75(1):47-60. 
12. Erickson-Schroth L, editor. Trans bodies, trans selves: A resource for the transgender community. Oxford University Press; 2014.

13. Joslin-Roher E, Wheeler DP. Partners in transition: The transition experience of lesbian, bisexual, and queer identified partners of transgender men. J Gay Lesbian Soc Serv 2009;21(1):30-48.

14. Alegria CA. Relationship challenges and relationship maintenance activities following disclosure of transsexualism. J Psychiatr Ment Health Nurs 2010;17(10):909-16.

15. Richards C, Bouman WP, Seal L, Barker MJ, Nieder TO, T'Sjoen G. Non-binary or genderqueer genders. Int Rev of Psychiatry 2016;28(1):95-102.

16. Spicer SS. Healthcare needs of the transgender homeless population. J Gay Lesbian Ment Health 2010;14(4):320-39.

17. Corliss HL, Rosario M, Wypij D, Wylie SA, Frazier AL, Austin SB. Sexual orientation and drug use in a longitudinal cohort study of US adolescents. Addict Behav 2010;35(5):517-21.

18. American Psychiatric Association. Diagnostic and statistical manual of mental disorders (DSM5®). American Psychiatric Publishing; 2013.

19. Drescher J, Byne W. Treating transgender children and adolescents: An interdisciplinary discussion. Routledge; 2014.

20. Shipherd JC, Green KE, Abramovitz S. Transgender clients: Identifying and minimizing barriers to mental health treatment. J Gay Lesbian Ment Health 2010;14(2):94-108.

21. Bockting W, Miner M, Rosser BS. Latino men's sexual behavior with transgender persons. Arch Sexual Behav 2007;36(6):778-86.

22. Benson KE. Seeking support: Transgender client experiences with mental health services. J Feminist Fam Ther 2013;25(1):17-40.

23. Lev AI. The ten tasks of the mental health provider: Recommendations for revision of the World Professional Association for Transgender Health's Standards of Care. Int J Transgenderism 2009;11(2):74-99.

24. Merryfeather L, Bruce A. The invisibility of gender diversity: Understanding transgender and transsexuality in nursing literature. Nurs Forum 2014;49(2):110-23.

$$
\begin{gathered}
\text { Acknowledgements - Nil } \\
\text { Source of Funding - Nil } \\
\text { Conflict of Interest - Nil }
\end{gathered}
$$

